\title{
Alianza del Pacífico: una comunicación de gobierno con mucho ruido
}

y pocas nueces

Pacific Alliance: government communication with "Much ado about nothing"

LUIS OLIVERA CÁRDENAS

Candidato a doctor en Ciencia Política y Gobierno y licenciado en Antropología por la Pontificia Universidad Católica del Perú (PUCP); Magister en Administración por el TEC de Monterrey, México. Entre el 2012 y el 2014 se desempeñó como director ejecutivo de la Agencia Peruana de Cooperación Internacional (APCI). 



\section{Alianza del Pacífico: una comunicación de gobierno con mucho ruido y pocas nueces}

\section{Pacific Alliance: government communication with "Much ado about nothing"}

Luis Olivera Cárdenas

PONTIFICIA UNIVERSIDAD CATÓLICA DEL PERÚ

lolivera@pucp.edu.pe

PALABRAS CLAVE / KEYWORDS

Alianza del Pacífico / comunicación gubernamental / diplomacia pública

Alianza del Pacífico / governmental communication / public diplomacy

\section{SUMILLA}

Desde su surgimiento el 28 de abril del 2011, la Alianza del Pacífico (AdP) ha constituido un símbolo de innovación, colaboración e iniciativa económica concertada para sus países socios (Chile, Colombia, México y Perú). Su continuidad es una de sus principales fortalezas, más allá de cambios presidenciales en los cuatro países miembros. Hoy la AdP puede mostrar logros en varios campos, entre ellos, la enorme expectativa generada en el mundo que se evidencia en los 55 países en condición de observadores de esta iniciativa. En este texto, la AdP es abordada desde la comunicación política (comunicación de gobierno y diplomacia pública), así como desde la perspectiva constructivista de las relaciones internacionales. Al analizar los logros reales de la AdP y lo que se dice de ella, tanto en los países socios como en el mundo, se constatan brechas sobre las que no se habla.
Con énfasis en el papel del Perú en la AdP, se propone una apropiación de esta y sus potencialidades en función de un efectivo proyecto nacional.

\section{ABASTRACT}

Since its beginning on April 28, 2011, the Pacific Alliance (PA) has been a symbol of innovation, collaboration and concerted economic initiative for its partner countries (Chile, Colombia, Mexico and Peru). Its continuity is one of its main strengths, beyond presidential changes in the four member countries. Today the PA can show achievements in several fields, among them, the enormous expectation generated in the world that is evident in the 55 observer countries of this initiative. In this text, the PA is approached from the Political Communication (government communication and public diplomacy), as well as from the constructivist perspective of Internation- 
al Relations. When analyzing the real achievements of the PA and what is said of it, in the partner countries and in the world, there are gaps about what is not spoken. With an emphasis on the role of Peru in the PA, we propose an appropriation of it and its potentialities seeking an effective national project.

\section{Introducción}

En el marco de la campaña presidencial en Estados Unidos de América el 2016, se manejó con gran frecuencia la expresión fake facts, fundamentalmente para caracterizar afirmaciones del candidato, luego presidente electo y hoy presidente, Donald Trump. La expresión hace referencia a datos falsos, más precisamente a la construcción de afirmaciones sobre la base de hechos sin evidencia de realidad, no comprobados y, usualmente, aceptados por muchos como ciertos.

Uno de los fake facts más difundidos, por lo menos en la gran mayoría de países de Sudamérica, es el que afirma que en el Campeonato Mundial de Himnos el primer lugar lo obtuvo la Marsellesa y que en segundo puesto quedó el himno del país desde donde sale dicha declaración. Esta afirmación la encontramos en Chile, Perú, Colombia, Ecuador, Brasil, Argentina, etc. Quienes se expresan así suelen hacerlo con gran fervor patriótico y la mayor disposición para defender hasta las últimas consecuencias lo aseverado, porque la dignidad nacional está en juego y porque es algo que todos saben.

La primera vez que escuché esta afirmación fue a inicios de los años 60, tomándola por cierta. Unos años después, aún en la escuela primaria, me sorprendí de que amigos, naturales de otros países, afirmaran lo mismo, aunque seguí convencido, porque todos lo sabían, que éramos segundos. Años más tarde, conversando con colegas ${ }^{1}$ en una reunión profesional internacional, nos reímos mucho al recordar esta afirmación y cómo, en todos los países, se contaba la misma historia. Incluso hicimos la broma al querido Jorge Enrique Hardoy de que en Argentina el cuento era diferente, ya que era el único país del mundo en el que su himno le ganaba a la Marsellesa.

Considero que con la Alianza del Pacífico (AdP) ocurre algo similar, es decir, los real facts existen, pero los fake facts son muchos y el público está convencido de su realidad.

Mi propósito en estas líneas es mostrar que existe una brecha entre las expectativas en torno a la AdP y la realidad. Incluso, que existen asuntos sobre los que no se habla.

1 Samuel Jaramillo y Pedro Santana de Colombia, Mario Vásconez y Fernando Carrión de Ecuador, Alfredo Rodríguez y Alex Rosenfeld de Chile, Humberto Vargas de Bolivia, Pedro Jacoby de Brasil y Jorge Enrique Hardoy y 
A continuación, presentaremos algunos elementos con relación a la comunicación de gobierno para luego referir los principales rasgos de la AdP, su origen, su desenvolvimiento, logros y vacíos. Finalmente, algunas reflexiones con relación a esta iniciativa con logros limitados, pero con una muy buena fama. Así mismo, comentaremos si una situación similar podría ocurrir con relación al ingreso del Perú a la Organización para la Cooperación y el Desarrollo Económicos (OCDE), como algunos quisieran.

\section{Comunicación de gobierno}

Partimos de coincidir con la definición que Riorda nos propone: "la comunicación gubernamental tiene un objetivo: generar consenso. Si la comunicación gubernamental no actúa bien, no hay consenso y si no hay consenso, no hay buena gestión” (2008, p.27).

No es sencillo para los gobiernos generar consensos en todos los temas, iniciativas o problemas frente a los que debe lidiar. En todo caso, la clave estaría en procurar el mayor consenso posible en la mayoría de asuntos en que se pueda. Una expresión del consenso es la ausencia de críticas, es decir, no es que necesariamente todos deban estar de acuerdo en un tema, sino que, en realidad, o no percibo que dicho tema me cambie la vida hoy o siento que nos genera prestigio, o que nos promete un futuro mejor, o todas las opciones juntas.
En esta perspectiva, nos parece clave señalar un elemento referido por Riorda con relación a la generación y vigencia de mitos y símbolos desde la comunicación gubernamental:

La comunicación gubernamental juega un papel clave en la construcción de una determinada cultura política. Se cultiva el rol deseado de los atributos de la ciudadanía y complementariamente, se crean condiciones materiales y no materiales para sostener esa ciudadanía, a través del desarrollo de símbolos y mitos que configuran elementos de identidad. (Riorda, 2011, p.106)

Entendemos que la AdP funciona como un mito, aunque no necesariamente movilizador, pero sí definitivamente percibido como algo positivo.

Para Riorda, la perspectiva teórica para aproximarse a la comunicación gubernamental es el construccionismo, así, señala:

El paradigma de gran parte de este trabajo puede situarse teóricamente dentro de la comunicación política en la línea del 'construccionismo', sosteniendo que la fundamental premisa que esta perspectiva invoca es que la realidad es un producto social, y que los primeros significados por los cuales la realidad es construida pertenecen al lenguaje. (...). 
El construccionismo crea o enfatiza problemas para avanzar con sus políticas, o bien, muchos de los verdaderos problemas son construcciones simbólicas y políticas para justificar el accionar del gobierno. El construccionismo gubernamental es diferente pues no sólo testea ambientes: los construye o al menos avanza en el intento. (2008, p.28)

Consideramos que la aproximación teórica de los autores constructivistas de las relaciones internacionales es cercana a la aproximación de Riorda. Queremos enfatizar el carácter de construcción social que tienen diversos fenómenos políticos y cómo la manera como son percibidos generan normas o realidades que existen en las mentes de las personas.

Recogemos los términos planteados por Finnemore para definir el constructivismo:

As the name suggests, scholars working in this vein share a general interest in social construction processes and their effects. They are concerned with the impact of cultural practices, norms of behavior, and social values on political life and reject the notion that this can be derived from calculations of interests (...). Preferences are strongly influenced and often constituted by social norms, culturally determined roles and rules, and historically contingent discourse. (1996, p.15)
Entendemos que predominan tanto en la postura del Estado peruano como en la AdP consideraciones relacionadas a construcciones simbólicas, normas, ideas, etiquetas, preferencias, etc., que vienen no de una opción racional sino de prejuicios, decires, supuestos sentidos comunes, etc.

Wendt, en su trabajo pionero "La anarquía es lo que los estados hacen de ella”, nos señala pistas para observar las normas y cómo aproximarnos a ese objeto de estudio:

Un principio fundamental de la teoría social constructivista es que la gente actúa hacia objetos, incluidos otros actores, sobre la base de los significados que los objetos tienen para ella. (1992, p.131)

Las identidades son la base de los intereses. Los actores no tienen una 'cartera' de intereses que llevan consigo, independientemente del contexto social; antes bien definen los intereses en el proceso de definir situaciones. (p.133)

(...) un segundo principio del constructivismo: que los significados en términos de los cuales se organiza la acción surgen de la interacción. (p.138)

Para nosotros, la manera como está presente el Perú en la AdP y el discurso que 
en ella presenta, deben ser apreciados desde una perspectiva construccionista / constructivista, con una comunicación política que enuncia mensajes que no contienen una propuesta de proyecto de sociedad, por lo que estaríamos frente a una comunicación política incompleta.

\section{Diplomacia pública}

También, desde la perspectiva de las relaciones internacionales, resulta relevante aproximarnos a la AdP como un espacio de diplomacia pública. En esta pista, nos apoyamos en la definición de Manfredi (2011): "La diplomacia pública tiene como objetivo el ejercicio de la influencia por parte de una entidad sobre un público extranjero mediante el desarrollo de estrategias de comunicación que incluyen los programas educativos, informativos y entretenimiento" (p.211).

Complementariamente, y ubicando el propósito de la diplomacia pública en la era de los medios sociales, Nicholas Cull (2011), reconocido académico en diplomacia pública, ubica el reto de esta en los siguientes términos: "the task of public diplomacy should evolve from one of speaking to one of partnering around issues with those who share the same objectives and empowering those whose will be credible with their target audience” (p.7).

Y si bien, como se presentará más adelante, la AdP cuenta con un considerado pro- grama de intercambio estudiantil, se trata de una línea de acción que no define a la AdP, aunque sí la refuerza.

La AdP constituye una iniciativa novedosa en diversos aspectos. Como se conoce, no cuenta con una institucionalidad autónoma; son los propios países, a través de sus instituciones, quienes manejan los diversos temas e iniciativas, sin generar una superestructura autónoma. Tampoco hay compromiso de cuotas o aportes regulares.

La idea de, a partir de la AdP, ganar prestigio para los países miembros, constituye una constante. Sin embargo, corresponde realizar algunos señalamientos:

- Los países de la AdP se presentan como grupo en aquellos espacios en los que aparecer de esa manera les genera un beneficio adicional al que obtendrían al hacerlo de manera individual. Es lo que suele ocurrir en contextos empresariales ya sea para abrir mercados o captar inversiones. Presentarse como la octava economía del mundo ayuda a ser escuchado.

- Sin embargo, también ocurre que, en algunos eventos, algunos países, además de una presencia como AdP, procuran una presencia propia. En este caso cada país desarrolla su propia diplomacia pública. Lo ocurrido en la Exposición Internacional de Milán (2015) es ilustrativo de esta situación: 
Chile, Colombia y México fueron expositores permanentes durante el periodo de la feria, 1 mayo a 31 octubre, sin embargo, Perú solamente tuvo una fugaz mención un día que se presentó, para darse a conocer, la AdP. La decisión de la ministra Rivas el 2014 de no estar presentes, contra la opinión de los funcionarios de Cancillería, aduciendo que era muy caro, llevó a nuestro país a perder oportunidades importantes.

- Una tercera línea sería la de desarrollar diplomacia pública hacia los países integrantes de la AdP. Ciertamente, la simultaneidad entre el desarrollo de la AdP y el manejo del diferendo marítimo ante la Corte Internacional de La Haya fue un enorme reto para las cancillerías de Chile y Perú. Como se señalará más adelante, la existencia de la AdP constituye algo muy importante para sectores específicos de los cuatro países, mejorando gracias a ella muchas e importantes relaciones, aunque no ha sido un hito para cambiar la opinión pública de cada país hacia los otros.

En la perspectiva que señala Cull, se trata de construir relaciones, asociarse, emprender retos comunes, consolidar alian- zas, diálogos, caminos en dos sentidos, etc. En esta pista la AdP tiene ventajas por su flexibilidad y por el hecho de no ser exclusivamente un esfuerzo de gobiernos, sino que involucra a diversos actores sociales, públicos y privados.

El reto de la diplomacia pública es comunicativo, “(...) debe emplear las estrategias comunicacionales para facilitar el contacto entre personas para facilitar el compromiso y la relación estable a largo plazo" (Manfredi, 2011, p.219).

Los diversos puntos que se presentan a continuación ilustran, desde nuestro punto de vista, tanto que la comunicación política practicada desde el gobierno peruano adolece de limitaciones y efectividad al no lograr levantar un mito, como que tampoco se practica una diplomacia pública hacia ninguno de los públicos interesados en conocer y vincularse a la AdP, ni al público interno, ni al de los países miembros de la alianza, ni al de los países observadores; a la larga, los que más interesarían en una perspectiva estratégica.

\section{Surge la AdP}

Luego de dos olas de integración en la segunda mitad del siglo $\mathrm{XX}^{2}$, en América Latina se mantiene la expectativa que juntos

2 La primera ola de integración en América Latina corresponde a las iniciativas de los años 60, como el Pacto Andino, que se inició en 1968, en plena vigencia del modelo cepaliano de industrialización por sustitución de importaciones; la segunda ola corresponde a la integración de mercados luego de la aplicación de las medidas del Consenso de Washington en la década de los años 80, el Mercado Común del Sur (Mercosur) que se inició en 1991. 
podemos lograr grandes resultados, aunque suele ser difícil delinear el porqué y el cómo de ese juntos.

Guillermo Fernández de Soto (2015, p.11), ex canciller de Colombia, identifica algunos desafíos a los que cualquier proceso de integración en América Latina debería responder:

- La pérdida del apoyo social a los procesos de integración, como resultado del desgaste de promesas incumplidas, donde la liberalización del comercio no ha traído el nivel de bienestar esperado. Somos una región donde las exportaciones están dominadas cada vez más por las materias primas, donde las exportaciones de bienes manufacturados han venido cayendo en su significación. Aspecto este que aplica a las exportaciones de los países que han intentado fortalecer sus procesos de integración.

- La rigidez de los esquemas institucionales, que no alcanzan a lidiar rápidamente con nuevas y cambiantes realidades, y la pesada burocracia que acarrea el manejo de la integración regional.

- Los nuevos retos que se presentan a escala global en el marco de una tecnología que avanza vertiginosamente requieren fortalecer la competitividad y la productividad de los países.
- En el sistema de comercio internacional existe una compleja fragmentación, que se refleja en AL [América Latina], donde la dificultad de avanzar se centra principalmente en los distintos enfoques sobre el rol del Estado en la economía, en la forma de insertarnos en la economía global y en los asuntos de seguridad regional.

Ante este contexto, los objetivos que se planteó la AdP, y que siguen vigentes, son:

OBJETIVO 1: Construir un área de integración profunda hacia la libre circulación de bienes, servicios, capitales y personas.

OBJETIVO 2: Impulsar un mayor crecimiento, desarrollo y competitividad de sus economías para un mayor bienestar, superación desigualdad socioeconómica e inclusión social.

OBJETIVO 3: Plataforma de articulación política, de integración económica y comercial, y de proyección al mundo, con especial énfasis en Asia-Pacífico.

Observando la AdP en su trayectoria y realidad hoy, podemos identificar que enfrentar estos retos ha estado, de alguna manera, presente. Lo que debe hacerse es romper con esquemas rígidos poniendo por delante el avance en acciones específicas más que generar una institucionalidad que toma tiempo crear y delimitar. Intentar nuevos caminos para abrir es- 
pacios que prometen en el comercio internacional. Mantener la idea que juntos somos más fuertes y llegamos más lejos.

Quizás el mayor logro de la AdP haya sido su continuidad, aun con cambios presidenciales en sus cuatro socios. Los presidentes que se han sucedido en estos ocho años son:

- Chile: Sebastián Piñera, Michelle Bachelet y Sebastián Piñera.

- Colombia: Juan Manuel Santos e Iván Duque.

- México: Felipe Calderón, Enrique Peña Nieto y Manuel López Obrador.

- Perú: Alan García, Ollanta Humala, Pedro Pablo Kuczynski y Martín Vizcarra.

Elementos que explicarían este logro serían: por un lado, la opción por una integración profunda, es decir, que determinados parámetros claves para el comercio internacional se convierten en comunes para los cuatro países, asunto que no implica mayor complicación ya que los cuatro ya tenían, al iniciar este proceso, sus respectivos Tratados de Libre Comercio (TLC) con EE.UU.; por el otro, un cierto perfil ideológico que no se hizo explícito más allá de constatar la común aproximación que todos tenían a la inserción en la economía interna- suscritos por cada uno de los países con diversos socios. Con relación a esto segundo punto, nunca se planteó una condición ideológica en los documentos de la AdP, salvo los compromisos que cada país ya tenía y que no recusó en ningún momento.

El surgimiento de la AdP como respuesta a la Alianza Bolivariana para Nuestra América - Tratado Comercial de los Pueblos (ALBA-TCP) es bastante evidente; sin embargo, sus promotores tuvieron el cuidado de no poner en los objetivos un alineamiento sobre el papel del Estado en la economía o asuntos similares.

Es en la III Cumbre Presidencial, realizada en Lima el 28 de abril del 2011 que se lanza, a través de la Declaración de Lima, la iniciativa para el surgimiento de la AdP. La IV Cumbre se realizó en el Observatorio Paranal, Antofagasta, Chile, el 6 de junio del 2012, y en ella se suscribió el Acuerdo Marco. El Protocolo Adicional al Acuerdo Marco se suscribe en la VIII Cumbre realizada el 10 de febrero del 2014 en Cartagena, Colombia.

En total, han tenido lugar 13 cumbres presidenciales, la última el 24 de julio del 2018 en Puerto Vallarta, México.

Este proceso de casi ocho años ha avanzado a la velocidad en la que todas las partes han estado de acuerdo. Así mismo, es de destacar el compromiso de los presidentes con esta iniciativa. 
En tanto, la AdP no tiene enemigos al interior de los cuatro países y desde fuera convoca gran simpatía e interés, todo lo que haga no está mal y aporta puntos positivos a las respectivas gestiones de los presidentes, al margen de lo que ocurra en otros campos.

Como señalamos, las cosas han marchado a su propio ritmo, el Acuerdo Marco entró en vigencia el 20 de julio del 2015, algo más de tres años después de haber sido suscrito; y el Protocolo Comercial entró en vigencia el 1 de mayo del 2016, algo más de dos años después de haber sido suscrito.

\section{Logros de la AdP}

En estos pocos años, la AdP ha alcanzado logros (Alianza del Pacífico [AdP], 2019), ello no se puede negar. Toca presentarlos a modo de plantear el piso desde el cual comentaremos los beneficios conseguidos y para quién.

- Desgravación del 92\% del comercio intrarregional y desgravación del 8\% restante de 3 a 17 años a partir del 2016.

- Realización de actividades conjuntas de promoción comercial, de inversiones y turismo.

- Se ha constituido el Consejo Empresarial de la AdP (CEAP), que participa del capítulo de compras guberna- mentales, promueve las cadenas de valor regionales, promueve la interoperabilidad de las Ventanillas Únicas de Comercio Exterior nacionales, identifica barreras no arancelarias intra-AdP y promueve la integración de mercados financieros. El CEAP ha sido una importante iniciativa del sector privado con el fin de dar recomendaciones a los gobiernos para construir una agenda de trabajo útil para la facilitación de negocios.

- Aun cuando los empresarios, básicamente de Colombia y Perú, venían conversando al respecto, es en el período de existencia de la AdP que se concretó la constitución del Mercado Integrado Latinoamericano (MILA), una plataforma de integración bursátil que promueve la integración financiera entre Chile, Colombia, México y Perú.

El 2009, las bolsas de valores de Colombia, Chile y Perú acuerdan establecer un mercado regional para compra y venta de acciones. El 30 de mayo del 2011 el MILA inicia operaciones. Esta es la primera iniciativa de integración bursátil transnacional sin fusión o integración corporativa a nivel global. México completó su adhesión al MILA en agosto del 2014. El MILA no es parte formal de la AdP ya que la integración bursátil es decisión de las empresas, aunque la integración financiera es una prioridad para la 
alianza. Los ministros de finanzas de la AdP se han reunido para consensuar sobre el tratamiento tributario en los mercados bursátiles. La integración financiera liderada por el sector privado requiere del apoyo del sector público para generar un marco institucional para la integración hacia la armonización regulatoria. El MILA es el segundo mercado más importante en América Latina y el Caribe.

- Una iniciativa específica de la AdP es la Plataforma de Movilidad Académica y Estudiantil. La idea de movilizar jóvenes que estudiarán durante un semestre en el ámbito de otros países de la AdP estuvo presente en las conversaciones de los presidentes desde las primeras cumbres. Anualmente, cada país se compromete a recibir hasta 100 estudiantes (50 por semestre). Los países receptores asumen los gastos de traslados, estudios, manutención y seguros de los estudiantes. Parte de los beneficiarios son académicos, profesores o doctorandos, realizando una estancia de docencia y/o investigación. Hasta 2018, la AdP ha beneficiado a 1840 personas.

- Suscripción del Acuerdo para el Establecimiento del Fondo de Cooperación y de la Red de Investigación Científica en Materia de Cambio Climático.

- Suscripción de un Acuerdo de Asisten- nales de los cuatro países recibir asistencia consular en aquellos Estados donde no haya representación diplomática o consular de su país de origen.

- Ocho sedes de embajadas compartidas (Argelia, Vietnam, Azerbaiyán, Ghana, Hungría, Irlanda, Marruecos y Singapur) y una oficina comercial conjunta (Estambul).

- Fortalecimiento de la Plataforma de Intercambio de Información Inmediata para la Seguridad Migratoria de la AdP, cuyo objetivo es facilitar la movilidad de personas entre sus países miembros.

- Facilitación del libre flujo de personas a través de la eliminación de visas de turismo y negocios.

- Creación del Programa de Vacaciones y Trabajo con miras a fomentar el intercambio cultural entre los jóvenes.

\section{¿Hasta dónde son fake facts?}

\section{Comercio en la AdP}

El comercio entre los países miembros de la AdP no se ha incrementado desde que esta se creó (Nolte, 2016, p.4). Una encuesta publicada por PricewaterhouseCoopers México (2014) en la que se preguntó a 120 empresarios y gente de negocios de Chile, Colombia, México y Perú sobre sus expectativas con relación a la AdP, mostró 
como resultado que eran muy altas en Colombia y Perú, más mesuradas en México y menos entusiastas en Chile.

La inexistencia de complementariedades económicas entre los países miembros es un obstáculo para el crecimiento del comercio al interior de la AdP. Más aún, la distancia geográfica y la inadecuada infraestructura de transporte constituyen otra barrera para incrementar el comercio o cadenas de valor intrarregionales. La AdP de alguna manera refuerza la posición de sus países miembros hacia terceros mercados, pero no necesariamente en América Latina.

\section{Empleo}

Este es un tema relevante porque da cuenta directamente de las condiciones de la economía y de la población. En diversos artículos, como el de Fernández (2015, p.13) y páginas web que tratan sobre la
AdP, uno de los datos que relievan es el del bajo desempleo; así, Fernández señala que para el conjunto de los cuatro países el promedio de desempleo es $6.5 \%$.

Sin embargo, el propio Fernández deja de lado, en torno a esta afirmación, un asunto que él mismo señala más adelante en su artículo: la informalidad en las economías de los países de la AdP.

Uno de los temas que sería importante fuera abordado por la AdP es el de la presentación de estadísticas sobre empleo. Las entidades oficiales de estadísticas de los cuatro países ${ }^{3}$, al momento de presentar cifras sobre este punto, tienen algunas diferencias, lo que obliga a trabajar sobre la base de información no segura para obtener datos comparables.

Interesa señalar que si bien en promedio el desempleo es bajo en los países de la AdP, al momento de identificar la mano de obra

Figura 1. Mano de obra no adecuadamente empleada como porcentaje de la Población Económicamente Activa (PEA) - 2018

\begin{tabular}{|l|c|c|c|c|c|}
\hline & Chile & Colombia & México & Perú & Total \\
\hline PEA & 8378000 & 22441388 & 49411764 & 16396400 & 96628422 \\
\hline $\begin{array}{l}\text { No adecuadamente } \\
\text { empleados }\end{array}$ & 837887 & 7203685 & 4199999 & 7542344 & 19783915 \\
\hline $\begin{array}{l}\text { No adecuadamente } \\
\text { empleados \% }\end{array}$ & 10.00 & 32.10 & 8.50 & 46.00 & 20.47 \\
\hline
\end{tabular}

Elaboración propia.

3 En Chile, el Instituto Nacional de Estadísticas (INE); en Colombia, el Departamento Administrativo Nacional de Estadística (DANE); en México, el Instituto Nacional de Estadística y Geografía (Inegi) (entre 1983 y el 2006 la "i" final hacía referencia a "Informática"; y aunque esta ya no esté a su cargo, se ha mantenido en el acrónimo); y en el Perú, el Instituto Nacional de Estadística e Informática (INEI). 
que declaró no estar adecuadamente empleada, corresponde a población que presenta características de subempleo por jornada o por ingresos. Usualmente se asume este dato como el que ilustra la informalidad, porque no existe registro de que esta mano de obra se encuentre laborando, ni figura en ningún registro de empleador, por lo que no accede a derechos laborales, no aporta a la seguridad social (por lo que no tiene acceso a prestaciones de salud), no aporta a ningún fondo previsional (por lo que no tendrá pensión al dejar de trabajar) y no paga impuestos.

El asunto se agrava en términos de modelo económico productivo porque, si bien el desempleo está más o menos uniformemente distribuido entre los cuatro países, la informalidad es tremendamente relevante en Perú y Colombia.

Así pues, la cifra de informalidad laboral se trata de un dato que se oculta. Es de alguna manera un fake fact porque no se coloca en el análisis. Otro dato que se oculta es el de la desigualdad, aunque, más allá que sea muy alta, termina siendo algo que no sorprende. En cambio una informalidad extendida hace pensar que algo no está bien, existiendo muchos efectos negativos para la economía como sistema cuando esta es significativa.

\section{Cooperación}

El Grupo de Trabajo de Cooperación existe desde el inicio de las conversaciones en preparación de la creación de la AdP. En estos años ha abordado, básicamente, cuatro temas:

Movilidad estudiantil y académica

Esta iniciativa se lanzó para su ejecución en el primer semestre del 2013. Rápidamente quedó en evidencia que México y Chile y, en menor medida, Colombia, tenían una base institucional para manejar un proyecto como este. Se estima que el costo de cada estudiante implica unos US\$ 10 ooo a cada país receptor, exclusivamente en gastos directos del estudiante; los gastos institucionales no han sido reportados por ninguno de los países. Obviamente no es lo mismo un trabajo adicional a un sistema que ya existe y funciona que crear un sistema con todos sus costos de aprendizaje e instalación. En el Perú, la Agencia Peruana de Cooperación Internacional (APCI), en el segundo semestre del 2012, trasladó la responsabilidad de la ejecución de la iniciativa al Programa Nacional de Becas y Crédito Educativo (Pronabec), recientemente creado en el Ministerio de Educación para manejar Beca 18. Al respecto, el Perú ha recibido pocas solicitudes de los otros miembros de la AdP pues nuestro país, y sus universidades, no son (re)conocidas como un espacio académico, teniendo la mayor demanda México, en segundo lugar Chile y algo más atrás Colombia.

En el balance general, el Perú sigue siendo un beneficiario neto de este programa de 
movilización estudiantil, pues son bastante más los peruanos que salen que los estudiantes extranjeros que vienen.

Investigación científica en cambio climático

Constituir una red científica sobre cambio climático fue una buena idea. Sin embargo, la iniciativa no tenía claridad de qué exactamente querían ni cómo llegar allí. Si bien los sistemas de investigación científica en los cuatro países tienen una raíz común rastreable a los años 60 y su promoción por parte de la Organización de las Naciones Unidas para la Educación, la Ciencia y la Cultura (Unesco), es claro que el tema del cambio climático no tenía la misma prioridad para todos los países. En el Perú, el incremento de fondos para investigación científica priorizó las ingenierías y la biomedicina. De un país a otro, los intereses de los académicos no coincidían exactamente. Tampoco se contaba con recursos para convencer a científicos en los cuatro países para que trabajaran en una misma perspectiva.

Finalmente, lo que se organizó a partir del segundo semestre del 2013 fue un grupo de trabajo con participación de académicos de los cuatro países para elaborar un proyecto conjunto que se presentara a la consideración de alguna entidad in- ternacional para que lo financiara. No fue fácil llegar a un acuerdo porque las condiciones específicas de los investigadores no eran similares en los distintos países, particularmente en el Perú donde los científicos interesados debían remar contra la corriente.

Hasta donde se conoce, un proyecto se concluyó. No se conoce a qué organizaciones internacionales se presentó. No ha trascendido que se estuviera llevando a la práctica.

\section{Vacaciones y trabajo}

Hacia fines del 2012, estando ya encausado el programa de movilización estudiantil, encargada la elaboración del proyecto de investigación sobre cambio climático a los científicos correspondientes y con la certeza de que el proceso para la creación del fondo de cooperación iba a tomar aún más tiempo por las numerosas consultas y aprobaciones en cada país, se planteó la pregunta: ¿Qué más podría hacerse como cooperación? La idea que rápidamente fue acogida y se comenzó a delinear como propuesta al Grupo de Alto Nivel (GAN) ${ }^{4}$ de la AdP, fue la de un voluntariado juvenil entre los países miembros.

La iniciativa fue planteada por Chile el 2012, quien ya había iniciado la operación

4 El Grupo de Alto Nivel de la Alianza del Pacífico (AdP), conformado por los viceministros de comercio exterior y de relaciones exteriores, es el encargado de supervisar los avances de los grupos técnicos, evaluar las áreas en las cuales se pueda avanzar y preparar una propuesta para la proyección y acercamiento externo con otros organismos o grupos regionales, en especial de la región Asia-Pacífico. 
de un programa de voluntarios y cooperantes bancado por su gobierno desde la Agencia Chilena de Cooperación Internacional (AGCI). De manera similar a otros países con una fuertemente proactiva política de colaborar con voluntarios y cooperantes, como EE.UU., Canadá, Japón, Corea, Holanda, Alemania y otros, Chile se propuso enviar cooperantes a diversos países, básicamente a aquellos prioritarios en su política exterior, como el Caribe anglófono y Paraguay.

En la modalidad con la que operó el programa en un inicio, quien recibió más voluntarios chilenos es el Perú. Son jóvenes en últimos años de escuela o primeros de universidad, ya organizados en grupos de proyección social / sensibilización social / responsabilidad social, usualmente promovidos por grupos religiosos que definen una acción de voluntariado, obteniendo apoyo normalmente de empresas para realizarla. Estos voluntarios llegan, habitualmente, a la región sur, básicamente a Cusco, Abancay, Puno y Arequipa.

Sobre la base de esa experiencia, a partir del 2015, el Grupo de Trabajo de Cooperación (GTC) de la AdP delinea un programa de voluntarios. Este programa está dirigido a jóvenes de entre 18 y 30 años de edad, nacionales de los países miembros, con el objetivo de movilizar anualmente a 48 jóvenes, 12 de cada país, desplazándose cuatro a cada uno de los otros tres países. El periodo de la acción voluntaria por cada convo- catoria tiene una duración mínima de dos semanas y máxima de cuatro semanas. El país receptor define la temática de las experiencias en las que participan los voluntarios. Para el financiamiento se emplea un mecanismo de gastos compartidos, como en el programa de intercambio estudiantil, de la siguiente manera: i) el país de origen asume el traslado por vía aérea desde el lugar de residencia hasta donde se realiza la experiencia, así como el seguro médico de los voluntarios; y ii) el país receptor asume alojamiento y manutención durante la estadía de los voluntarios.

Cabe recalcar sobre este punto que si bien este programa resulta muy positivo, lo que es real también es que solo Chile tiene un programa propio de voluntariado y que dicho voluntariado solo llega al Perú. Colombia y México no tienen previsto, en el horizonte de su política de cooperación, contar con un programa de voluntarios pues tienen otras urgencias y prioridades. El Perú, por su parte, cuenta con recursos si se propusiera desarrollar un programa como este, sin embargo, esta experiencia no forma parte del menú de opciones para promover su imagen en otros países. Así pues, esta es otra oportunidad desaprovechada para desarrollar de manera ordenada y de largo plazo nuestra diplomacia pública.

\section{Fondo de Cooperación de la AdP}

Esta fue una iniciativa planteada conjuntamente por México y Chile, a partir de 
una experiencia mexicana en el manejo de sus recursos de cooperación. Tan pronto México identifica un socio, país u organismo internacional intergubernamental, define un plan estratégico y un plan de acción, luego crea un fondo especial para ese plan de trabajo que es manejado también por la contraparte con la no objeción de México. Así, si algún proyecto se ralentiza por razones ajenas a la Agencia Mexicana de Cooperación Internacional para el Desarrollo (Amexcid) o la contraparte técnica mexicana, los recursos no se pierden por cierre de año (teniendo que volver a solicitar fondos). México y Chile cuentan con un fondo conjunto para realizar proyectos de Cooperación Internacional para el Desarrollo (CID) en Haití y el Caribe anglófono.

La reunión de directores de las agencias de cooperación de la AdP, realizada en Ciudad de México el 26 de julio del 2012, abordó este tema. Teniendo en cuenta la experiencia de México y Chile, los directores propusieron algo similar, constituyendo un fondo de la AdP con un aporte de US\$250 ooo por cada uno de los cuatro países. Esta propuesta fue inmediatamente acogida por la reunión de cancilleres y ministros de Comercio Exterior que se realizó al día siguiente y posteriormente por los presidentes en la siguiente cumbre, con lo que los cuatro países se comprometieron en el acuerdo.

El acuerdo consistía en contar con un fondo de cooperación de la AdP para, por consenso al más alto nivel, desarrollar cooperación técnica, como AdP, en los espacios que fuera necesario de acuerdo a los objetivos estratégicos de la AdP.

Chile y México no tuvieron complicaciones políticas ni de procedimiento para cumplir todo lo que su legislación e instituciones les exigieron. Los problemas se presentaron en Colombia y Perú.

En Colombia el problema se presentó en los numerosos candados desarrollados para la administración de fondos públicos. ¿Cómo era eso de aportar a un fondo de un organismo internacional intergubernamental que no tiene personería jurídica propia, que no tiene sede, por tanto no tiene cuentas bancarias a nombre propio? El mecanismo diseñado por los directores de cooperación para mantener la lógica de no generar estructuras independientes era que la administración del fondo rotara entre los países, junto con la rotación de la coordinación del GTC. Como todas las decisiones se tomarían por consenso y los gastos estarían orientados a actividades sin existir gasto corriente, se entendía que no había dificultad en operar de esa manera. Para Colombia un problema adicional a los ya mencionados era el hecho de que el dinero saliera al concluir su coordinación. Según su legislación, ya era bastante complicado el ingreso de los fondos al país en una situación tan peculiar como para que un año después salieran direccionados a una institución pública peruana (como 
por ejemplo la APCI). Tomó tiempo pero, finalmente, Colombia logró diseñar una solución y concretarla.

En el Perú las objeciones vinieron principalmente del lado político más que de procedimientos. Desde que Pedro Pablo Kuczynski (quien terminará siendo presidente de la República) estuvo a cargo del Ministerio de Economía y Finanzas (MEF) durante el gobierno del presidente Alejandro Toledo, los fondos solamente se pueden crear por ley y, adicionalmente, deben estar explícitamente referidos en la Ley Anual de Presupuesto y Gasto Público, y las leyes que aprueba el Congreso. Para la administración de los recursos, es decir, en lo que correspondía al Poder Ejecutivo, no había problemas ni con el monto ni los procedimientos. Correspondió a la APCI y a la Cancillería realizar un lobby muy fino para ganar respaldo tanto en la Comisión de Relaciones Exteriores, en la de Presupuesto y Cuenta General de la República, así como en la de Economía, Banca, Finanzas e Inteligencia Financiera del Congreso. No es que el gobierno no contara, junto con sus aliados, con una mayoría en el Congreso para conseguir la aprobación del fondo de cooperación de la AdP, sino que simplemente mencionar "cooperación”, “aporte”, "apoyar desarrollo fuera del territorio" iba a generar la siempre intemperada reacción de algunos congresistas. Con sigilo y transparencia, sin festinar ningún procedimien-
Sin embargo, el fondo aún no opera. Aparentemente, el 2015 habría habido planteamientos de uno de los países para que la cooperación se orientara hacia el interior de la AdP y no como AdP hacia afuera. Sería un asunto clave pendiente.

Así pues, sería otro fake fact afirmar que el fondo existe, sí está, pero no opera. Han pasado más de cuatro años que se decidió crear el fondo y poco más de dos años desde que los cuatro países se alinearon en el punto de partida para operar con él.

\section{¿Qué estaría ocurriendo con la AdP?}

\section{AdP, alianza estratégica o grupo de arribistas}

Si bien los países miembros de la AdP comparten intereses económicos, el común denominador en otros temas no es tan claro. Para algunos la AdP puede caracterizarse como una herramienta minilateral arribista, mediante la cual los países miembros buscan mejorar sus estatus en el escenario internacional.

Paul, Larson y Wohlforth (2014) definen estatus como:

(...) collective beliefs about a given state's ranking on valued attributes... (y argumentan que) in international politics, status manifests itself in two distinct but related ways: as membership in a defined club of ac- 
tors, and as a relative standing within such a club.

Los cuatro países de la AdP han creado un exclusivo club de libre comercio (solo países con TLC con los cuatro pueden integrarlo en el futuro), posicionado la marca de la nueva organización como una alianza de Estados con mercados abiertos, respeto de la legalidad, garantía de derechos de propiedad y una dinámica económica que opera como una puerta hacia Asia.

En términos de Nolte (2016), los integrantes de la AdP se presentan como los "chicos buenos" o "buenas economías", comparados con los "chicos malos" o "malas economías" de la Alianza Bolivariana para Nuestra América (ALBA) y otros países Estadocéntricos de América Latina.

El alto número de países observadores en la AdP puede ser interpretado como un indicador de que los países miembros han tenido éxito con su estrategia de posicionamiento de marca y arribismo.

En ese sentido, el número de países observadores crece cada año. En realidad, nadie ha señalado, hasta ahora, con claridad, cuál es el beneficio de ser un país observador. La sensación de que de pronto ganamos un montón y objetivamente no nos cuesta nada parece que es lo que anima a los países a ser parte de este ¿exclusivo club? de turiferarios de los New Kids on the Block. La AdP está teniendo la gran capacidad de conseguir que todos, salvo los que viven en el error, como los países del ALBA, hablen bien de la iniciativa y de haber logrado un espacio sin habérselo disputado a nadie, por lo que no ha habido contusos en el camino.

De todos los confines del mundo observan a la AdP. Nadie ha sido incorporado y, aparentemente, eso lo hace más atractivo. De pronto todo estalla por los aires si comienzan a aceptar a unos y no a otros como miembros plenos. Otra buena política ha sido que a nadie se ha rechazado como observador. Se ha enunciado las condiciones en términos del papel del Estado y el mercado, por lo que quien pide incorporarse está aceptando esa identidad.

Luego de la cumbre de julio del 2018, se anunció el inicio de negociaciones con Australia, Canadá, Singapur y Nueva Zelanda, encaminadas a acceder a la categoría de "Estados asociados". Hasta el momento no hay anuncio formal de en qué consiste la condición de "asociado", ni tampoco cómo es el procedimiento para serlo, y si otros países podrían pasar a esa condición. Lo más probable es que se siga incrementando el número de observadores y que no cambie el número de miembros plenos. 
Figura 2. 55 países observadores de la AdP

\begin{tabular}{|c|c|l|}
\hline Sudamérica & 4 & Uruguay, Argentina, Ecuador y Paraguay \\
\hline Centroamérica y el Caribe & 8 & $\begin{array}{l}\text { Costa Rica, Panamá, El Salvador, Guatemala, Honduras, Trinidad y } \\
\text { Tobago, República Dominicana y Haití }\end{array}$ \\
\hline Norteamérica & 2 & Canadá y Estados Unidos de América \\
\hline Europa & 28 & $\begin{array}{l}\text { Alemania, Austria, Bélgica, Bielorrusia, Croacia, Dinamarca, Eslovaquia, } \\
\text { Eslovenia, España, Finlandia, Francia, Georgia, Grecia, Hungría, Italia, } \\
\text { Lituania, Noruega, Países Bajos, Polonia, Portugal, Reino Unido, } \\
\text { República Checa, Rumania, Serbia, Suecia, Suiza, Turquía y Ucrania }\end{array}$ \\
\hline Asia & 9 & $\begin{array}{l}\text { China, Corea del Sur, Emiratos Árabes, India, Indonesia, Israel, Japón, } \\
\text { Singapur y Tailandia }\end{array}$ \\
\hline Oceanía & 2 & Australia y Nueva Zelanda \\
\hline África & 2 & Marruecos y Egipto \\
\hline
\end{tabular}

Junto con el señalamiento de arribismo que plantea Nolte, también refiere que lo que ha ocurrido con la AdP es un posicionamiento de marca. La marca AdP es valorada como positiva, pero no conocemos cuál es el producto inigualable que promueve. Los países miembros son conscientes de ello y lo aprovechan tratando de administrarlo con prudencia para no gastarlo o quebrarlo.

\section{Específicamente Colombia y Perú}

El peso del arribismo y el posicionamiento de marca son más fuertes en Colombia y Perú. Ello explicaría que la AdP esté muy presente en sus medios y en su opinión pública como un logro y una herramienta decisiva para el futuro. Esto se debería a que ambos son miembros de la debilitada Comunidad Andina (CAN), que ha perdido interés para otros países, y por los problemas internos que, de tiempo en tiempo, confrontan, lo que tiene un impacto negativo en la percepción que las otras naciones tienen sobre ellos. Sin embargo, ambos países también tienen un gran potencial económico y están tratando de ubicarse en el contexto regional, al mismo tiempo que buscan el modelo correcto para mejorar su estatus internacional.

\section{Como iniciativa de integración}

Se trata de un nuevo esquema de integración en América Latina en el que lo prioritario viene siendo el contenido económico de la integración y en el que se pone los acentos en aquellos sectores que significan una profunda relación económica entre los países que integran la AdP. 
No se puede decir que los esquemas de integración tengan una única dimensión, sino que existen diversas dimensiones dentro de un mismo proceso. Aunque la dimensión económica es la prioritaria y esencial en la conformación de la AdP, ello no impide que aparezcan o vayan apareciendo elementos que correspondan a dimensiones diferentes de la económica. Los avances en materia económica quizá favorezcan la aparición y presencia de los aspectos sociales de la integración y determinen la construcción de la dimensión política necesaria para hacer efectivos los avances en el campo económico. (Díaz Galán, 2015).

En la pista de lo planteado por Heine (2016, p.46), la AdP constituye una iniciativa con ruptura y continuidad con anteriores iniciativas de integración en la región:

La AdP, con todas sus especificidades y diferencias con otros esquemas de integración regional y subregional, sigue estando anclada en un estilo muy sui generis de diplomacia colectiva latinoamericana que ha surgido en el curso de las últimas dos décadas. Ella se basa en una cierta visión de mundo, una Weltansschauung que reconoce la existencia de un sistema regional latinoamericano, cuya autonomía debe ser preservada y cultivada, que es manejado por los gobiernos nacionales por medio de una variedad de esquemas de integración y cooperación.
La formulación general según la cual se pretende una integración profunda en lo económico, en lo político y en lo social no es suficiente para dar contenido a cada una de estas dimensiones. En el fondo, es difícil encontrar instrumentos en los que se expresen avances muy significativos en la dimensión política o social en la AdP.

El énfasis en la integración económica opaca cualquier otra dimensión de la integración y cualquier avance que se produzca en lo político y en lo social, quedando condicionados por los logros que se alcancen en la integración económica y comercial. Aun así, en diversos espacios se expresa un notable interés por favorecer y facilitar la movilidad de las personas en el espacio que cubre la AdP, lo que conllevaría a la adopción de acuerdos que incidan en las dimensiones política y social, sobre los que, aparentemente, no existe mayor interés, o posibilidad, en avanzar. Un ejemplo de ello es el caso del ejercicio profesional, pues en la AdP no está planteada la homologación de estudios superiores entre los países miembros (a diferencia de la homologación de estudios escolares, planteada en la alianza y vigente en los cuatro países, ya que todos forman parte del Convenio Andrés Bello).

\section{Un par de real facts}

A partir de un estudio realizado por el Centro de Investigación y Docencia Eco- 
nómica (CIDE) 5 (Morales, Maldonado y Schiavon, 2016) sobre conocimiento y expectativas en torno a la AdP, se ha determinado que el conocimiento con relación a la existencia de la AdP es bajo:

Dos resultados sobre las sociedades de los países miembros de la AdP. Por un lado, más de la mitad de la población en los cuatro países no conocen o no tienen una opinión sobre la Alianza. Por el otro, hay variaciones en el grado de conocimiento y desconocimiento entre los países. Mientras que en Colombia $47 \%$ de la población sí conoce y emite una opinión sobre la AdP (muy parecido al casi $46 \%$ de Chile), en México sólo el 30\% de la población conoce y es capaz de valorarla. Perú está en una situación relativamente mejor con $40 \%$ de conocimiento entre su población. (Morales, Maldonado y Schiavon, 2016, p.148)

Con relación a las expectativas, Morales y otros plantean lo siguiente:

Ahora bien, entre quienes dijeron conocerla, ¿qué tan favorable o desfavorable es la opinión pública de los países miembros sobre la AdP? Los re- sultados de esta variable permiten señalar algunas diferencias y semejanzas entre estas sociedades. Primero, la mejor opinión la tienen los chilenos, con 57.3 puntos de promedio ${ }^{6}$, a quienes les siguen los ciudadanos de Perú y México, con 53.5 y 51.4 puntos, respectivamente. La opinión menos favorable la tienen los colombianos, con 50.5 puntos de media. Segundo, tomando estas medias dentro de la escala de 0 (muy desfavorable) a 100 (muy favorable), en general los ciudadanos latinoamericanos hacen una valoración bastante neutral sobre la AdP, ya que todas son cercanas a los 50 puntos. (2016, p.149)

A partir del estudio realizado por el CIDE y procesado por los autores, recogemos las sugerencias que estos plantean:

Si se desea que este esquema de integración prospere y cuente con apoyo social amplio, pueden ponerse en marcha algunas alternativas de política pública. El primer paso sería invertir recursos en mejorar el nivel de conocimiento de los ciudadanos sobre el ámbito internacional en general y la AdP en particular (...).

\footnotetext{
5 Se trata de un estudio promovido por el Centro de Innovación y Desarrollo Emprendedor (CIDE) para el cual contó con la colaboración de la Universidad de Chile, en Chile; de la Universidad de Los Andes, en Colombia; y de la Pontificia Universidad Católica del Perú (PUCP), en Perú. En Chile la encuesta se aplicó a 1206 personas entre el 1 de diciembre del 2014 y el 15 de febrero del 2015. En Colombia la encuesta se aplicó a 1500 personas entre el 30 de marzo del 2015 y el 4 de abril de ese año. En México la encuesta se aplicó a 2400 personas entre el 8 de noviembre del 2014 y el 22 de diciembre de ese año. Finalmente, en el Perú la encuesta se aplicó a 1200 personas entre el 18 de octubre del 2014 y el 28 de noviembre de ese año.

6 Utilizando las respuestas de aquellos que sí emitieron una opinión sobre la AdP, los autores crearon una variable numérica continua con el objeto de analizar la valoración de la AdP en cada una de las sociedades.
} 
El segundo paso sería informar mejor a los ciudadanos de cada uno de los países miembros de la AdP acerca de los beneficios que ésta puede generarles en términos de bienestar personal, en especial sobre cómo la liberación de los flujos económicos y la cooperación entre los cuatro países repercuten en mayores niveles de desarrollo nacional e individual. (Morales, Maldonado y Schiavon, 2016, p.160-161)

Finalmente, otro dato real lo constituye el hecho de que lo más dinámico en esta iniciativa de integración es el Comité Empresarial, incluso con países observadores lo más dinámico es este comité. En noviembre del 2013, en paralelo a la Cumbre Iberoamericana realizada en Panamá, los cancilleres de los cuatro países se dirigieron a un extenso auditorio de empresarios centroamericanos y caribeños en el marco de un Encuentro Empresarial de la AdP.

\section{Finalizando}

El recorrido presentado en torno a la AdP nos muestra que su realidad es bastante menos de lo que, en general, el público imagina o supone que es. Es cierto que como no nos toca directamente, el público asume que estando lejos no hará daño. Sin embargo, el problema radica en que no son pocos los que piensan que la AdP sacará al Perú del espacio de potencia media latinoamericana.
Ello tiene que ver, junto con otros aspectos, en la manera en cómo se ha construido el discurso de la AdP. Podemos afirmar que la diplomacia pública ha sido exitosa, ha generado expectativa en el mundo y en nuestras propias sociedades. Aun así, se mantiene la pregunta si así lo quisieron los jefes de Estado que lanzaron el proceso o, como sospechamos, fue una feliz coincidencia que animó el entorno y satisfizo a sus promotores.

En la perspectiva de García Canclini, tal como lo expresa en una entrevista publicada en la revista EURE, podríamos afirmar que para amplios sectores, la AdP es un imaginario:

En términos muy generales podemos decir que imaginamos lo que no conocemos, o lo que no es, o lo que aún no es. En otras palabras, lo imaginario remite a un campo de imágenes diferenciadas de lo empíricamente observable. Los imaginarios corresponden a elaboraciones simbólicas de lo que observamos o de lo que nos atemoriza o desearíamos que existiera. (Lindón, 2007, p.90)

Imaginario en el sentido de que se trata de lo que deseamos, no necesariamente real, o no totalmente real, observable; pero, sin embargo, existe y muchos actúan en función de ello, por lo que logra desarrollarse y hacerse realidad en alguna medida. Tocará revisar los mensajes de la estrategia comunicativa y también 
lo observable de la AdP para contrastarlo con los imaginarios de García Canclini y las normas de Wendt.

Y si bien la cúspide de la moda de la AdP ya disminuyó, no ha desaparecido. Hoy en el Perú se reemplaza el mito para ascender de liga por el del ingreso a la OCDE. Los otros tres socios de la AdP, por su parte, ya están en la OCDE, están en otro escalón, con otros interlocutores.

Lo del ingreso a la OCDE plantea para el Perú retos complicados, entre ellos, reconocer que si Chile, Colombia y México están ahí no es por estar en la AdP, están porque en los diversos aspectos que la OCDE exige mínimos ellos los cumplen.

Para el Perú fue fácil ser parte de la AdP y beneficiarse durante varios años, por lo menos del $2011 \mathrm{al}$ 2016, al ser parte de un grupo exitoso y con buena fama. No tuvo que hacer nada particular ni especial. La buena prensa que tuvo la AdP benefició al Perú e hizo creer a algunos, entre ellos a más de un presidente, que sin hacer nada se iba a llegar lejos, dejando el subdesarrollo e incorporándose a otro escalón.

Los gobiernos, en algo el de Alan García Pérez, pero sobre todo el de Ollanta Humala Tasso, manejaron bien la buena fama de la AdP para hacerla aparecer como un gran logro de su accionar. Era más ruido que nueces.
Otro reto complicado para el ingreso del Perú a la OCDE es la exigencia de cumplir mínimos en diversos aspectos institucionales, estando el país lejos de ellos. La informalidad, la precariedad institucional, la debilidad de la sociedad civil generan una brecha para la que no se aprecia iniciativas sólidas para cerrarla.

Fake facts or Real facts? Como siempre suele ocurrir, las cosas no son negro o blanco, son grises, y muchos tonos de gris. Sin embargo, es claro que la AdP, como está planteada hoy, no le va a cambiar la vida a los 100 millones de pobres de los cuatro países miembros. Con certeza nunca hemos encontrado juntos estos dos facts: $\mathrm{AdP}=100$ millones de pobres. Esto es parte de lo que es importante que cambie.

Sería tremendamente grave que los integrantes de las sociedades de los cuatro países miembros de la AdP termináramos pensando que esta es la panacea, no debe ocurrir lo mismo que con el Campeonato Mundial de Himnos, que nunca existió realmente pero que está fuertemente presente en la cabeza de mucha gente en nuestros países.

La AdP es lo que es y deberíamos emprender el trabajo de delinear, en conjunto, qué queremos que sea para todos. 


\section{REFERENCIAS}

Alianza del Pacífico (AdP). (2019). Alianza del Pacífico. El poder de la Integración. Recuperado de https://alianzapacifico.net/

Cull, N. J. (2011). Wikilieaks, public diplomacy 2.0 and the state of digital public diplomacy. Place Branding and $\mathrm{Pu}$ blic Diplomacy, (7), 1-8. https://doi. org/10.1057/pb.2011.2

Díaz Galán, E. C. (2015). La Alianza del Pacífico: Características y dimensiones de un nuevo proceso de integración en América Latina. Revista Electrónica Iberoamericana, 9 (2), 1-20.

Fernández de Soto, G. (2015). La Alianza del Pacífico: Un ejemplo para la integración regional. Tribuna Abierta, (39), 7-18.

Finnemore, M. (1996). National Interests in International Society. New York: Cornell University Press.

Heine, J. (2016). Sigla nueva en sopa de letras: raíces y ramificaciones de la Alianza del Pacífico. Revista Mexicana de Política Exterior, (106), 35-48.

Lindón, A. (2007). ¿Qué son los imaginarios y cómo actúan en la ciudad? Diálogo con Néstor García Canclini. Revista EURE, 33 (99), 89-99. https://doi.org/10.4067/S025071612007000200002

Manfredi Sánchez, J. L. (2011). Hacia una teoría comunicativa de la diplomacia pública. Comunicación y Sociedad, 24 (2), 199-225.

Morales Castillo, R.; Maldonado, G. y Schiavon, J. A. (2016). Las bases sociales de la Alianza del Pacífico. Revista Mexicana de Política Exterior, (106), 133-164.
Nolte, D. (2016). The Pacific Alliance: Nation-Branding through Regional Organisations. GIGA Focus / Latin America, (4). Recuperado de https:// bit.ly/31J8658

Paul, T. V.; Larson, D. y Wohlforth, W. C. (Eds.). (2014). Status in World Politics. Cambridge: Cambridge University Press. https://doi.org/10.1017/ CBO9781107444409

PricewaterhouseCoopers México. (2014). La Alianza del Pacífico, una nueva era para América Latina. Ciudad de México: Club de Conocimiento.

Riorda, M. (2008). Gobierno bien pero comunico mal: análisis de las rutinas de la comunicación gubernamental. Reforma y Democracia, (40), 27-41.

Riorda, M. (2011). La comunicación gubernamental como comunicación gubernamental. Revista POLITAI, 2 (3), 96-111.

Wendt, A. (1992, 2009). La anarquía es lo que los estados hacen de ella: La construcción social de la política del poder. En A. Santa Cruz (Ed.), El constructivismo y las relaciones internacionales (pp. 125-174). Ciudad de México: Centro de Investigación y Docencia Económica (CIDE). 